\title{
Multicultural competency instrumentation: A review and analysis of reliability generalization
}

Todd W. Dunn

Timothy B. Smith

Brigham Young University, tbs@byu.edu

Jared A. Montoya

Brigham Young University

Follow this and additional works at: https://scholarsarchive.byu.edu/facpub

Part of the Counseling Psychology Commons

\section{Original Publication Citation}

Dunn, T., Smith, T. B., \& Montoya, J. (2006). Multicultural competency instrumentation: A review and analysis of reliability generalization. Journal of Counseling and Development, 84, 471-482.

\section{BYU ScholarsArchive Citation}

Dunn, Todd W.; Smith, Timothy B.; and Montoya, Jared A., "Multicultural competency instrumentation: A review and analysis of reliability generalization" (2006). Faculty Publications. 2029.

https://scholarsarchive.byu.edu/facpub/2029 


\section{RUNNING HEAD: MULTICULTURAL COMPETENCY INSTRUMENTATION}

Dunn, T., Smith, T. B., \& Montoya, J. (2006). Multicultural competency instrumentation: A review and analysis of reliability generalization. Journal of Counseling and Development, 84, 471-482.

Multicultural Competency Instrumentation:

A Review and Analysis of Reliability Generalization

Todd W. Dunn, Timothy B. Smith, and Jared A. Montoya

Brigham Young University 


\begin{abstract}
This manuscript reviews instruments designed to assess multicultural competency and reports the results of a reliability generalization study. Data obtained from 89 research manuscripts were analyzed to assess the average internal consistency coefficients for each of the instruments and to determine the degree to which the internal consistency differed across populations and settings. Additional psychometric properties are qualitatively reviewed for commonly used instruments and five other measures of multicultural competency that had not been previously reviewed in the literature. The results indicate that the most widely used instruments have generally acceptable internal consistency reliability across different populations and settings. Limitations of the research being conducted on the topic of multicultural competencies are identified, and recommendations for future research are provided.
\end{abstract}




\section{Multicultural Competency Instrumentation:}

A Review and Analysis of Reliability Generalization

Amidst general progress in moving toward culturally competent mental health services, pressures to define the construct of multicultural competence and provide evidence for its utility and validity in improving intervention outcomes continue to increase. Stanley Sue (2003) acknowledged this state of the field, asking:

What is the evidence for the effectiveness of cultural competence? How is culture competency defined and measured? There are compelling reasons to address these questions. Administrators of mental health systems and agencies want to hire culturally competent providers and to train their providers to be culturally competent. Many providers sincerely want to develop cultural proficiencies. But how are these tasks to be accomplished? For example, how can culturally competent providers be identified? What measures of cultural competence are there?...We should be particularly interested in the evidence base for these questions (p. 966).

Central to providing an evidence base for the questions posed by Stanley Sue is the issue of multicultural competency assessment. In other words, if counseling professionals are to evaluate multicultural competence, they need to know what instruments are available to assess the construct and, more importantly, be confident in the reliability and validity of the scores from those instruments. Research evaluating multicultural competence is indeed "a cornerstone of the multicultural counseling literature” (Reynolds, 2001, p. 833). 
Since the development of multicultural competency instruments in the late 1980's and early 1990’s (LaFromboise, Coleman, \& Hernandez, 1991; Ponterotto, Reiger, Barrett, \& Sparks, 1994), researchers have been able to assess multicultural competence from the perspective of the therapist, client, and third party observer (e.g., Arthur, \& Januszkowski, 2001; Fuertes, \& Brobst, 2002; Worthington, Mobley, Franks, \& Tan, 2000). Such instrumentation forms a critical part of research investigating multicultural competency development, cross-cultural training effectiveness, and the influence of cultural variables on counseling process and outcome (e.g., Bellini, 2002; Christensen, 2002; Constantine, 2000, 2002a, 2002b; Fuertes, et al., 2002; Wheaton, \& Granello, 1998).

Recent literature searches revealed that over 800 manuscripts have addressed multicultural competence in mental health professional training and assessment. Although other authors (e.g., Ponterotto, et al., 1994) had previously reviewed this literature when it was quite small, the proliferation of manuscripts on multicultural competence necessitates a current evaluation of the state of the field to provide counselor educators, counselors, and researchers with an objective guide of the instruments' strengths and limitations over time and across populations and settings. Reliability generalization is a method for evaluating score reliability across many studies (e.g., Vacha-Haase, 1998). Such an analysis and an accompanying narrative review would respond to Sue's (2003) question about measures of multicultural competence, generate recommendations for improving those measures, and inform the way that counselors and counselor educators assess multicultural competence.

Review of Previous Instrumentation Reviews 
In 1994, Joseph Ponterotto and colleagues conducted the first narrative review of multicultural competency instrumentation, including the Multicultural Counseling Inventory (MCI) (Sodowsky, Taffe, Gutkin, \& Wise, 1994), the Cross-Cultural Counseling Inventory-Revised (CCCI-R) (LaFromboise, et al., 1991), the Multicultural Counseling Awareness Scale: Form B (MCAS) (Ponterotto et al., 1996), and the Multicultural Awareness Knowledge Skills Scale (MAKSS) (D'Andrea, Daniels, \& Heck, 1991). They found that each instrument followed the model of multicultural competency developed by Derald Wing Sue and colleagues (Sue, Arredondo, \& McDavis, 1992; Sue, et al., 1982) and possessed promising psychometric characteristics. Of note, only four studies were reviewed for the CCCI-R, two for the MCAS, and one for both the MCI and MAKSS. The reviewers concluded that further systematic validation was needed before each instrument was implemented in professional and academic settings.

Pope-Davis and Dings (1995) also published a critique of three of the four instruments reviewed by Ponterotto et al. (1994): the MAKSS, the MCI, and the MCAS. This report found the MAKSS to have a rather unclear interpretative approach, the MCI to have a fairly straight forward interpretative approach, and the MCAS to have a complicated interpretive approach. Suggestions for item revision and scale interpretations were made for each instrument in both manuscripts (Pope-Davis \& Dings, 1994, 1995).

A subsequent narrative review by Ponterotto and Alexander (1996) found the MCI, MAKSS, MCAS, and CCCI-R to be sensitive to therapist change as a result of training, although only the MCI and MCAS were found to be sensitive to increased levels of multicultural experience. The reviewers also cited important evidence of divergent 
validity in that the CCCI-R was found to measure a different construct than general counseling efficacy. A more recent narrative review by Boyle and Springer (2001) indicated that the MCI, MAKSS, MCAS, and CCCI-R were all "easy to administer and score, moderate in length (about 25 minutes to complete), and inexpensive” (p. 65). However, this review recommended the use of more ethnically and economically diverse samples in the continued psychometric validation of these instruments.

Because the counseling literature has focused predominantly on four particular instruments of multicultural competence (CCCI-R, MAKSS, MCI, and MCAS), those four instruments are briefly described here. The CCCI-R (LaFromboise, et al., 1991) allows clients to rate counselors across 20 uni-dimensional items with such content as “Counselor is at ease talking to me” and "Counselor demonstrates knowledge about my culture.” The MAKSS (D’Andrea, et al., 1991) consists of 60 self-report items on three subscales: (a) Knowledge (e.g., “At the present time, how would you rate your understanding of the following term? 'Ethnicity””), (b) Skills (e.g., “How would you rate your ability to effectively secure information and resources to better serve culturally different clients?”), and (c) Awareness (e.g., “In general, how would you rate your level of awareness regarding different cultural institutions and systems?”). A revised version of this instrument, consisting of 33 items (10 items each for the Awareness and Skills subscales and 13 items for the Knowledge subscale) has recently been published (MAKSS-Counselor Edition-Revised or MAKSS-CE-R; Kim, Cartwright, Asay, \& D’Andrea, 2003). The MCI (Sodowsky, et al., 1994) allows individuals to rate themselves on 40 statements comprising four subscales: multicultural Knowledge, Skills, Awareness, and Relationship. Lastly, the 32-item Multicultural Counseling Knowledge 
and Awareness Scale (MCKAS, a revision of the MCAS; see Ponterotto, Gretchen, Utsey, Rieger, \& Austin, 2002) evaluates therapist self-reported competence in multicultural Knowledge (e.g., "I am aware of institutional barriers which may inhibit minorities from using mental health services”) and Awareness (e.g., "I believe all clients should maintain direct eye contact during counseling”).

Recent empirical research using these four multicultural competency instruments has raised several issues in need of further investigation. First, these instruments may be associated with tendencies of participants to respond in socially desirable ways (e.g., Constantine \& Ladany, 2000). Second, the factor structure of these instruments has been called into question. Constantine, Gloria, and Ladany (2002) evaluated the factor structure of the MCI, MAKSS, and MCKAS through confirmatory and exploratory factor analyses. They found that only a two-factor solution was supported, somewhat substantiating the two-factor structure of the MCKAS and disconfirming the structures of the three-factor MAKSS and four-factor MCI (Constantine, et al., 2002). Third, researchers have been cautioned in interpreting the results of self-report instrumentation like the MCI, MAKSS, MCKAS, and CCCI-R (self-report version) because they might actually measure multicultural counseling self-efficacy, not respondents’ demonstrated ability to counsel diverse populations (Constantine, et al., 2000, 2002). Fourth, selfreport instruments of multicultural competence are inconsistently related to observerrated multicultural competence (e.g., Worthington, et al., 2000). Fifth, observer-rated multicultural competence is related to the verbal content of the multicultural counseling vignette, with counselors who simply talk more about multicultural issues receiving higher ratings (e.g., Worthington et al., 2000), raising the criticism that multicultural 
competence as assessed by observer-rated instruments may be more a function of verbal content than of culturally adapted skills. Sixth, low concurrent validity between measures of multicultural competence and the high magnitude of subscale intercorrelations have also "raised questions about the development and definition of the constructs being measured” (Kocarek, Talbot, Batka, \& Anderson, 2001, p. 494).

With the scholarly contributions of these reviews and empirical investigations in mind, the stage is set for a more comprehensive quantitative synthesis of the current literature. All four of the narrative reviews cited previously referenced the limited body of research conducted prior to 1995, and all four called for the improvement of existing measures and/or for the development of novel multicultural competency instruments. Based on the substantial increases in the multicultural competency literature since 1995 and the questions raised in recent empirical reports about the four most commonly used measures of multicultural competency, descriptions of more recently developed multicultural competency instruments and additional analyses of the most commonly used instruments both appear warranted.

As one method for evaluating the reliability of scores across different populations and settings, the meta-analytic technique of reliability generalization (Vacha-Haase, 1998) will be used in this study. A benefit of this quantitative method is that comparisons across studies using different sample sizes and different demographic characteristics can be made, which are particularly germane to the topic of multicultural competence, given criticisms of restricted sample size and participant demographics (Boyle, et al., 2001). Qualitative descriptions of instrument-specific information regarding validity are also provided. Overall, this manuscript attempts to provide a 
comprehensive review of multicultural competency instrumentation by reporting: (a) analyses identifying the most commonly used multicultural competency instruments, (b) a reliability generalization analysis of the internal consistency reliability coefficients obtained across studies using multicultural competency instruments, (c) additional psychometric information obtained from the surveyed literature for the MCI, MAKSS, MCKAS, and CCCI-R, and (d) descriptions of five multicultural competency instruments not previously reviewed in the published literature.

Method

\section{Literature Survey of Multicultural Competency Instrumentation}

The professional literature was searched to identify published and unpublished studies assessing multicultural competency. Computerized searches of ten bibliographic databases (PsychINFO, Social Work Abstracts, Sociological Abstracts, Social Science Search, ERIC, ProQuest, Family \& Society Studies Worldwide, PsycArticles, Academic Search Elite, and CINAHL) yielded over 800 studies using the keyword roots multicultur, cross-cultur or cultur crossed with the roots competenc, proficien or train. Additional studies were identified by expanding database searches to include multicultural competency instrument names, by soliciting prolific authors on the topic for unpublished material, and by performing manual searches of article reference sections. Inclusion criteria required that each study be written after 1990 in English and include some form of multicultural competency assessment. Multicultural competency assessment was defined as any measure of mental health professionals’ ability to work with individuals across differences in culture, race, or ethnicity. 


\section{Data Coding}

Information reported in the obtained studies was coded so as to be subjected to statistical analyses. Categorical variables coded were: (a) publication outlet (e.g., journal article, book chapter, dissertation), (b) research design (e.g., cross-sectional, longitudinal, archival, comparison groups, experimental, pre- to post-test comparison), (c) sample selection procedure (i.e., convenience or random), (d) participant professional/employment status, and (f) name of multicultural instrument and subscales. Coded variables with continuous level data were: (a) mean age of the participants, (b) number of participants in the sample, (c) race/ethnicity of participants, (d) percentage of female participants, and (e) the internal consistency reliability coefficient reported for scores on each scale/subscale used in the study.

Each article obtained was coded separately by two advanced graduate students with over two years experience in multicultural and meta-analytic research. Because all variables coded were reported verbatim in the studies, inter-rater reliability coefficients exceeded .90 for all variables coded (using Cohen’s kappa [1960] for categorical variables and intra-class correlations for continuous variables). Discrepancies in coding were resolved through discussion and consensus.

\section{Results}

\section{Descriptive Characteristics across Studies}

Of the over 800 total articles identified on the general topic of multicultural competence, only 137 (less than 17\%) explicitly conducted a quantitative assessment of individuals' multicultural competence. Of these 137 studies, 68 were published in refereed journals and 69 were unpublished master's theses, doctoral dissertations, or 
conference presentations. A total of 29 multicultural competency instruments were used in the 137 studies, but only 6 of the 29 instruments identified were used in more than one study (see Table 1). The vast majority of studies (112 or 82\%) employed self-report forms of multicultural competency assessment. Eight studies combined self-report and observer-rated assessment instruments, and 17 studies employed only observer-rated assessment instruments. Self-report instruments used most often were the MCI, MAKSS, MCKAS, GSEDS, and Multicultural Counseling Competence and Training Survey (MCCTS; Holcomb-McCoy, \& Myers, 1999). The only observer-rated measure of multicultural competence used more than once was the CCCI-R.

The descriptive characteristics of all studies are presented in Table 1. Studies most often employed cross-sectional designs to obtain convenience samples with an average of 147 participants per study. Across all studies, data were provided for a total of 61,154 participants. Participant gender was reported in 127 studies (93\%), with an average participant composition of $71 \%$ females. Participant race was reported in 123 studies (90\%), with an overall breakdown of 71.8\% European Americans, 8.7\% African Americans, 6.1\% Hispanic/Latino Americans, 3.8\% Asian Americans, 1.0\% Native Americans, 5.1\% Other Americans, and 3.2\% International. The mean age of participants across all studies was 35.9 years, and 91\% of the participants were middle to upper middle class.

\section{Reliability Generalizability Analysis of Multicultural Instrumentation}

Only 89 (65\%) of the 137 research studies using a measure of multicultural competency reported internal consistency reliability coefficients. From these 89 studies, coders extracted a total of 322 internal consistency reliability coefficients $(M=.795$, $S D$ 
$=.11$ ). Instruments with more than two coded internal consistency reliability coefficients are presented in Table 2. Because the authors of the MCAS have encouraged colleagues to use the updated MCKAS (Ponterotto et al., 2002), only information representing the MCKAS is reported. With exception of the relationship subscale of the MCI and the awareness subscale of the MAKSS, average internal consistency reliability coefficients for all instruments and subscales exceeded the value of .70 recommended for instruments assessing self-reported opinions, attitudes, and beliefs (Guilford \& Fruchter, 1978; Ponterotto, 1996).

To determine if the internal consistency reliability coefficients reported for the scores on each instrument were stable across time and across study characteristics, reliability generalization analyses were conducted using all continuous and categorical variables coded. Statistical analyses were only run for those measures with at least five reported internal consistency reliability coefficients. No significant correlation $(p>.05)$ was found between the reliability coefficients reported for the scores on any of the multicultural competence measures and number of participants in the research sample or any of the other continuous variables coded (participants' average age, percentage of female participants, percentage of participants from different racial/ethnic groups, or the year of publication of the study). Similarly, analyses of variance (ANOVAs) revealed no significant differences $(p>.05)$ in the magnitude of the reliability coefficients reported for scores on any of the multicultural competence measures across the categorical variables coded (research design, sample selection procedure, participant professional/employment status, and participant socioeconomic status). Review of the Most Widely Used Instruments: MCI, MAKSS, MCKAS, and CCCI-R 
Psychometric characteristics not quantitatively analyzed were gathered from the 137 studies for the most commonly used instruments, the MCI, MAKSS, MCKAS, and CCCI-R. As seen in Table 3, the intra-subscale correlation coefficients reported across several studies for the MCI, MAKSS, and MCKAS were moderate in magnitude, ranging from .25 to .51. Instrument subscales apparently maintained some degree of independence in their assessment of the general overarching construct of multicultural competency.

To determine the convergent validity between the MCI, MAKSS, MCKAS, and CCCI-R, a multitrait-multimethod matrix (Campbell, \& Fiske, 1959) was constructed by averaging the correlations found in seven research studies between similar and dissimilar instrument full-scale scores and subscales (see Table 3). The patterns in the results obtained indicated that: (a) correlation coefficients between similar traits across different instruments were highest (average $r=.46$ ), and (b) average correlation coefficients between dissimilar traits across the same instrument (average $r=.40$ ) were nearly the same as the average correlation coefficients between dissimilar traits across different instruments (average $r=.39$ ). Of note, full-scale scores from the MCI, MAKSS, and MCKAS were highly correlated with one another, but only the self-report version of the CCCI-R was associated with the MCI, suggesting self-report and observer-rated measures of multicultural competency assess different constructs (e.g., Constantine, 2001a; Constantine, et al., 2000; Velez, 2003; Worthington et al., 2000). Although strong correlations ( $r$ ranged from .43 to .65) were generally observed between similarly named subscales from the MCI, MAKSS, and MCKAS, the notable exception to this trend was 
the correlation between the Awareness subscales from the MCI and MCKAS, which was only $r=.05$.

In terms of their construct validity, the surveyed literature provided little evidence regarding the factor structures of the MCI, MAKSS, MCKAS, and CCCI-R. Adequate goodness of fit indices have been estimated for only the MCKAS (Ponterotto et al., 2002), and the factor structures of the MCI and of the MAKSS have been questioned (Constantine, et al., 2002; Cumming-McCann, 1999; Garcia, 1997; Gutierrez, 1996; Ponterotto, \& Alexander, 1996). Exploratory factor analysis supported a one-factor structure of the CCCI-R (Barone, 1997; LaFromboise, et al., 1991), but no confirmatory factor analysis using data from the CCCI-R was found in the literature. Of note, authors of the MAKSS have recently responded to these criticisms, using exploratory and confirmatory factor analyses to develop the revised MAKSS-CE-R, which demonstrated comparative fit indices greater than .95. While Kim et al. (2003) report evidence of adequate reliability and validity, there have been no additional studies published using the MAKSS-CE-R, so further information regarding this newly revised measure will be forthcoming.

Some evidence in the literature suggested multicultural competency was associated with social desirability. For instance, the MCI, MAKSS, and CCCI-R (both self-report and observer-rated versions) were each significantly correlated with measures of social desirability, with average correlation coefficients ranging from .21 to .24 (Boero, 2002; Constantine, 2001b; Constantine, et al., 2000; Granello, \& Wheaton, 1998; Martinez, 1997; Robinson, 1999; Sodowsky, Kuo-Jackson, Richardson, \& Corey, 1998; Wheaton, et al., 1998; Worthington, et al., 2000). For this reason, some scale developers 
have suggested concurrently administering a measure of social desirability so that associated variance could be controlled (Sodowsky, et al., 1998). However, across several studies, the MCKAS was not significantly correlated with measures of social desirability (Constantine, 2000; Constantine, et al., 2000; Constantine, et al., 2001; Ponterotto, et al., 2002).

Some evidence in the literature also suggested that the CCCI-R was highly correlated with measures of general therapist competency (average $r=.64$; Coleman, 1998; Constantine, 2001c, 2002b). However, this finding was not surprising given that several items of the CCCI-R directly assess general therapist competency. Review of Recently Developed Multicultural Competency Instrumentation

This section describes measures of multicultural competence that have not been evaluated in a previously published review. These instruments are the Multicultural Counseling Checklist (for School Counselors) (Holcomb-McCoy, 2004), the Multicultural Counseling Competence and Training Survey (Holcomb-McCoy, et al., 1999), the Multicultural Counseling Ethics and Assessment Competency Scale (Byington, Fischer, Walker, \& Freedman, 1997), the Survey of Graduate Students' Experiences with Diversity (Talbot, 1992), and the Multicultural School Psychology Counseling Competency Scale (Rogers, \& Ponterotto, 1997). Despite providing alternative assessments of multicultural competency, instruments were omitted from this review if they have not been used in the past ten years to assess multicultural competency (e.g., Test of Cultural Knowledge; Cameron, 1990), were not specifically designed to measure multicultural competency (e.g., Miville-Guzman Universality-Diversity Scale; Miville, et al., 1999; Cross-Cultural Sensitivity Scale; Pruegger, \& Rogers, 1994), or 
were a modified form of some preexisting competency instrument already reviewed in the literature (e.g., Scale to Assess Attitudes, Knowledge, Skills; Martinez, 1995). Multicultural Counseling Checklist (for School Counselors). A checklist for use in evaluating the self-reported multicultural competence of school counselors was recently developed based on a theme analysis of the multicultural and school counseling literature (Holcomb-McCoy, 2004). The checklist consists of 51 statements representing nine content categories: counseling, consultation, understanding racism and student resistance, assessment, understanding racial identity development, family counseling, social advocacy, school-family-community partnerships, and cross-cultural interpersonal interactions. The checklist's author did not specify item development procedures and did not provide any information regarding reliability or validity. Further research is necessary before use of the checklist would be justified.

Multicultural Counseling Competence and Training Survey (MCCTS). The MCCTS (Holcomb-McCoy, et al., 1999) is a self-report measure of perceived multicultural competence. Developed using the multicultural competencies adopted by the Association for Multicultural Counseling and Development, the MCCTS requires responses to 29 demographic items and 32 behaviorally based items (e.g., "I am able to discuss how my culture has influenced the way I think”). A unique feature of the MCCTS is its response protocol. Counselors respond in three ways to each of the 32 items by rating their competence, assessing the adequacy of their corresponding training, and recording the location of such training. The behavioral based questionnaire appears to assess counselors along five factors (Multicultural Knowledge, Awareness, and Skills, 
Racial Identity Development, Definitions) with internal consistency reliability coefficients ranging from .66 to .92 for each factor (Holcomb-McCoy, et al., 1999).

Multicultural Counseling Ethics and Assessment Competency Scale (MCEACS).

The MCEACS is a 17-item self-report measure of counselor multicultural competency, with a unique focus on ethical awareness (2 items) and assessment (7 items) (Byington, et al., 1997). Counselors rate their knowledge, skills, and awareness of these two topics with five-point, Likert-type scales. To date, only preliminary steps have been taken to assess this instrument's internal consistency reliability $(\alpha=.92)$, face validity, and concurrent validity with the MAKSS ( $r=.69$; Byington, et al., 1997). The focus of 7 of the 17 items on assessment issues seem to make the MCEACS uniquely suited to measure that aspect of practice, but its applicability to general clinical practice may therefore be restricted. Survey of Graduate Students' Experiences with Diversity (GSEDS). The GSEDS is a self-report measure developed to evaluate students' experiences with and attitudes about diversity with respect to race, gender, and gay/lesbian issues (Talbot, 1996). The original scale was designed for use with students in student affairs programs, but researchers have since adapted this scale for use with counseling trainees (Kocarek et al., 2001) and graduate faculty (Talbot, \& Kocarek, 1997).

Although this scale is not based on multicultural competencies described in the counseling literature (e.g., Arredondo, et al., 1996), it appears to assess related issues. Specifically, three subscales allow respondents to rate their actual knowledge (20 items), skills (12 items), and comfort (20 items) with diversity on four and five-point Likert-type scales. However, it should be noted that the knowledge subscale used concrete examples of diversity literature from the early 1990s (e.g., participants are asked to rate their level 
of knowledge pertaining to specific topics, such as Parker's Multicultural Action Planning, that are no longer widely discussed in the multicultural literature) that would need to be updated for this scale to be appropriate for current use.

With regard to its psychometric qualities, research has reported acceptable testretest $(r=.70, .84, .86$; Talbot, 1992) and internal consistency reliability coefficients $(\alpha$ $=.89, .81, .92$; Kocarek, et al., 2001) for scores on the knowledge, skills, and comfort subscales, respectively. Also, Kocarek et al. report moderate concurrent validity coefficients between the knowledge and skills subscales of the GSEDS, MCAS, and MAKSS, providing preliminary evidence that these subscales measure similar constructs. Nevertheless, until the items from the knowledge subscale are updated to reflect the current literature, only use of the skills and comfort subscales is advised.

Multicultural School Psychology Counseling Competency Scale (MSPCCS). The MSPCCS was designed as a means for faculty members to rate the multicultural competence of graduate student trainees in school psychology programs (Rogers, et al., 1997). The 11 items of the MSPCCS were drawn directly from Sue et al.’s (1982) original multicultural competencies, and factor analysis supports a uni-dimensional interpretive approach. Acceptable internal consistency reliability has been reported for this measure ( $\alpha=.88$; Rogers, et al., 1997). The MSPCCS is the only observer-rated measure of multicultural competence located in the literature besides the CCCI-R, but its use is currently restricted to the evaluation of school psychology graduate programs.

\section{Discussion}

As Arredondo and Toporek (2004) have stated, "multicultural competency is becoming a way of life” (p. 53) in the counseling profession, partly because of an 
increased emphasis by governing bodies (i.e., American Counseling Association) to provide culturally responsive services to underserved populations. Of course, multiculturally competent counseling services require constant "refinement, development, and validation based on continuing and new sociocultural and political issues that impinge on the lives of individuals and families” (Arredondo, et al., 2004, p. 50). Because the needed research to support this advancement relies on the qualities of the instruments used, scrutiny of instrumentation is warranted. Implications for Multicultural Counseling Competency Assessments

The four most widely used measures of multicultural competence to date (MCI, MAKSS, MCKAS/MCAS, and CCCI-R) were initially developed over a decade ago, prior to the behavioral anchoring of the competencies (Arredondo, et al., 1996). Although two of these instruments have recently undergone promising revisions (MAKSS-CE-R and MCKAS), insufficient evidence currently exists to ascertain whether the new versions have overcome some of the difficulties observed in this review. First of all, multicultural competency subscales tended to lack evidence of divergent validity. The finding of moderately high correlations between dissimilar subscales continues to "raise questions about the development and definition of the constructs being measured" (Kocarek, et al., 2001; p. 494). Similarly, although the four most commonly used instruments all utilized some aspect of Sue et al.'s $(1982,1992)$ tripartite model as a foundation, only the two recently revised instruments have demonstrated a factor structure with adequate goodness of fit (the two-factor structure of the MCKAS and three-factor structure of the MAKSS-CE-R). These trends in the extant research suggest 
that additional refinement of the construct of multicultural counseling competency accompany the refinement of the measures designed to assess that construct.

Central to the issue of construct validity is the association of multicultural competency measures with tendencies among participants to endorse statements seen as socially appropriate. In sensitive and value-laden topics such as multicultural competence, this concern appears somewhat justified given that the correlations of the MCI, MAKSS, and CCCI-R with measures of social desirability reach levels of statistical significance (Constantine, et al., 2000). However, the present literature review uncovered that the amount of shared variance between the scores on multicultural competency instruments and measures of social desirability was moderately small (average $r^{2}=.04$ ). Furthermore, research in the area of personality assessment has found that: (a) social desirability represents a valid source of variance that has a minimal effect on construct validity (Smith, \& Ellingson, 2002) and (b) correcting for social desirability may remove substantive variance and unduly lower the predictive ability/clinical utility of self-report instruments (McCrae, \& Costa, 1983). These issues will need to be considered in future research to further clarify the role that social desirability plays in multicultural competency assessment.

A third issue for ongoing refinement is the apparent high degree of overlap between general counseling competency and multicultural competency, which has prompted some to claim these constructs are somewhat synonymous traits of "good" counselors (e.g., Coleman, 1998). A possible reason for this finding is the fact that multicultural competency instruments (e.g., MCI, CCCI-R) include items that assess general counseling competency, thereby diminishing their ability to partial out construct 
specific variance. Interestingly, Constantine (2002b) reports that ratings of counselor multicultural competency account for a significant portion of variance in predicting counseling satisfaction after the variance associated with ratings of general counseling competency is controlled. Consequently, Constantine suggests some uniqueness may exist between these constructs in predicting service satisfaction for ethnically diverse clients. If this is the case, the field would benefit from an understanding of those specific aspects of multicultural competence that are unique from general counseling skills and are important to counseling process and/or outcome. To accomplish this, researchers could consider removing items that assess general counseling competence from analyses so that the construct assessed is more specific to multicultural counseling competence. Similarly, research studies could enter specific scale items describing multicultural competence into a regression model predicting variables such as client perceptions of counselor after first entering into the model general counseling competence (independently observed, to reduce shared rater variance). Alternatively, researchers could conduct group comparison designs in which they vary the level of multicultural competence and the level of general counseling competence and then evaluate the magnitude of the correlations obtained between observer-rated multicultural competence and independently rated general counseling competence across conditions. Qualitative research and counseling process research investigating what specific variables best predict multicultural competence vs. general counseling competence should also be considered.

Despite the several limitations characteristic of the multicultural competency literature, the most commonly used instruments were found to yield scores with generally 
acceptable internal consistency coefficients over time and across populations.

Specifically, the results of the reliability generalizability analyses indicate that the MCI, MAKSS (currently the MAKSS-CE-R), CCCI-R, and MCKAS may appropriately be used across many populations and settings, such as by instructors of courses designed to enhance multicultural counseling competence (including practicum and internship supervision). In short, there is apparently no need to delay ongoing research while refinements to existing measures of multicultural competency are being performed.

\section{Directions for Future Research}

In advocating that additional research be conducted, we also note the several limitations that this review uncovered in the field and suggest avenues of future inquiry associated with each. First, similar to the findings of previous narrative reviews, we note that the vast majority of research has been conducted with European American practitioners and graduate students. Although this study reports no differences in the reliability coefficients reported across studies conducted with practitioners vs. those conducted with students or across studies with diverse racial/ethnic compositions, concerns over instrument validity and inherent cultural biases persist. Additional research may be beneficial to verify the factor structures and differential item functioning (e.g., Roussos, \& Stout, 1996) across participants of different racial/ethnic backgrounds to ensure that the measures are indeed assessing the same constructs across groups of people.

Another limitation in the literature reviewed is the lack of attention given to the client's perception of culturally competent counseling. Of the 137 studies that quantitatively assessed multicultural competency in this study, only 8 used ratings from 
clients. Of these eight studies, only four used actual clients, and only one did not use college students (i.e., Thorn, 1996). It appears as though the most important perceptions of multicultural competency, those of the client, are being overlooked. Further qualitative and quantitative investigations of client perceptions are warranted to better understand the role multicultural competency plays in therapy. Such research might lead to the development of novel or extensions of existing competency paradigms that are specifically designed for the clinical setting (e.g., Pope-Davis, et al., 2002). These new competency paradigms could be used to determine specific domains of therapist multicultural competency that impact treatment process and outcome from the client's point of view. Items from existing instruments can be selected, or items can be developed, that assess these domains, leading to the development of instrumentation that is better suited to establish external validity for the field.

General limitations of the literature reviewed are that the vast majority of studies are cross-sectional, and half of the research manuscripts identified on the topic remain unpublished. Although research design did not moderate the magnitude of the reliability coefficients reported across studies, these observations speak to the depth/quality and context of research being conducted on the topic. Clearly, more sophisticated research questions and carefully controlled studies are warranted. Darcy, Lee, and Tracey (2004) suggest that researchers “expand their methodological toolboxes, thus allowing for a better match between research questions posed and associated designs” (p. 149). For example, they introduce an idiothetic methodology that bridges normative and idiographic methodologies and allows generalizing research results to both groups and individuals, possibly facilitating a "more complex understanding of multicultural issues 
as they pertain to counseling” (p. 139). As a contextual factor, the number of unpublished manuscripts suggests that much of the research is done by graduate students (doctoral dissertations and master's theses from 54 graduate schools were included in this study) that are not part of systematic research programs focused in this area. Counselor educators could mentor students to increase the methodological sophistication of future dissertations/theses.

Moreover, although the literature reviewed is replete with calls to investigate the relationship between counselor multicultural competency and treatment process and outcomes, studies of this nature remain scarce. Of the 137 studies that quantitatively assessed multicultural competence, less than $10 \%$ investigate cultural influences on treatment process and outcome, while almost 70\% focus on either evaluating multicultural training or studying the general construct itself. The field would progress faster by taking the necessary steps to evaluate how multicultural competence relates to counseling outcomes, thereby establishing criterion validity, the major source of validity that has yet to be adequately documented in the literature. Initial steps in that direction could include: (a) soliciting the funds required to conduct rigorous effectiveness and efficacy studies, (b) focusing research agendas to examine evidence-based interventions across theoretical cultural constructs and/or individual ethnic groups (Sue, 2003), and (c) allocating space in professional journals for studies that deal with this issue through the use special sections or by emphasizing the acceptance of such research for publication.

Although this review also highlighted five measures of multicultural competence that had not been reviewed previously, those particular measures all need additional psychometric validation before widespread use. Furthermore, there is currently no 
psychometric evidence that those less frequently used scales offer more promising alternatives to the most commonly used scales (the MCI, MAKSS, MCKAS, and CCCIR), two of which (MAKSS-CE and MCKAS) have recently undergone extensive revisions. Although developing new measures can benefit the field, efforts thus spent can also have the unintended effect of generating a host of mediocre measures, rather than focusing efforts on answering the truly crucial questions proffered by Stanley Sue (2003): "What is the evidence for the effectiveness of cultural competence? How is culture competency defined?...How can culturally competent providers be identified?” (p. 966). We believe that additional short-term effort in refining the definition and measurement of multicultural counseling competence can facilitate long-term labors devoted to those more important questions. 


\section{Author Note}

Todd W. Dunn and Jared Montoya, Department of Psychology, Brigham Young University. Timothy B. Smith, Department Counseling Psychology and Special Education, Brigham Young University. Todd W. Dunn is currently a doctoral candidate at the University of Texas Southwestern Medical School.

Correspondence concerning this article should be addressed to Todd W. Dunn, Division of Psychology, UT Southwestern Medical School, 5323 Harry Hines Blvd, Dallas TX 75390-9044. Email: Todd.Dunn@utsouthwestern.edu 


\section{References}

Arredondo, P., \& Toporek, R. (2004). Multicultural counseling competencies = ethical practice. Journal of Mental Health Counseling, 26, 44-55.

Arredondo, P., Toporek, R., Brown, S. P., Jones, J., Locke, D. C., Sanchez, J., \& Stadler, H. (1996). Operationalization of the multicultural counseling competencies. Journal of Multicultural Counseling and Development, 24, 42-78.

Arthur, N., \& Januszkowski, T. (2001). The multicultural counselling competencies of Canadian counsellors. Canadian Journal of Counselling, 35, 36-48.

Barone, S. L. (1997). Assessing the cross-cultural counseling competencies of counseling psychologists: A quantitative and qualitative analysis (Doctoral dissertation, Pennsylvania State University). Dissertation Abstracts International, 57, 5058.

Bellini, J. (2002). Correlates of multicultural counseling competencies of vocational rehabilitation counselors. Rehabilitation Counseling Bulletin, 45(2), 66-75.

Boero, J. V. (2002). Construct validity of the multicultural counseling inventory: The impact of ethnic identity, social desirability bias, and modern racism (Doctoral dissertation, University of South Dakota, 2002). Dissertation Abstracts International, 63, 2573.

Boyle, D. P., \& Springer, A. (2001). Toward a cultural competence measure for social work with specific populations. Journal of Ethnic \& Cultural Diversity in Social Work, 9(3-4), 53-71.

Byington, K., Fischer, J., Walker, L., \& Freedman, E. (1997). Evaluating the effectiveness of a multicultural counseling ethics and assessment training. Journal of Applied Rehabilitation Counseling, 28(4), 15-19. 
Cameron, S. C. (1990). An analysis of multicultural counseling courses: Selected outcomes (Doctoral dissertation, Purdue University, 1990). Dissertation Abstracts International, 50, 3482.

Campbell, D. T., \& Fiske, D. W. (1959). Convergent and discriminant validation by the multitrait-multimethod matrix. Psychological Bulletin, 56, 81-105.

Christensen, C. H. (2002). Therapist cultural sensitivity and premature termination rates with ethnic minority adolescents (Doctoral dissertation, University of Akron, 2001). Dissertation Abstracts International, 62, 4776.

Cohen, J. (1960). A coefficient of agreement for nominal scales. Educational and Psychological Measurement, 20, 37- 46.

Coleman, H. L. K. (1998). General and multicultural counseling competency: Apples and oranges? Journal of Multicultural Counseling and Development, 26, 147-156.

Constantine, M. G. (2000). Social desirability attitudes, sex, and affective and cognitive empathy as predictors of self-reported multicultural counseling competence. Counseling Psychologist, 28, 857-872.

Constantine, M. G. (2001a). Predictors of observer ratings of multicultural counseling competence in Black, Latino, and White American trainees. Journal of Counseling Psychology, 48, 456-462.

Constantine, M. G. (2001b). Multiculturally-focused counseling supervision: Its relationship to trainees' multicultural counseling self-efficacy. Clinical Supervisor, 20, 87-98. 
Constantine, M. G. (2001c). The relationship between general counseling self-efficacy and self-perceived multicultural counseling competence in supervisees. Clinical Supervisor, 20, 81-90.

Constantine, M. G. (2002a). Racism attitudes, White racial identity attitudes, and multicultural counseling competence in school counselor trainees. Counselor Education and Supervision, 41, 162-174.

Constantine, M. G. (2002b). Predictors of satisfaction with counseling: Racial and ethnic minority clients' attitudes toward counseling and ratings of their counselors' general and multicultural counseling competence. Journal of Counseling Psychology, 49, 255-263.

Constantine, M. G., Arorash, T. J., Barakett, M. D., Blackmon, S. M., Donnelly, P. C., \& Edles, P. A. (2001). School counselors' universal-diverse orientation and aspects of their multicultural counseling competence. Professional School Counseling, 5, 13-18.

Constantine, M. G., Gloria, A. M., \& Ladany, N. (2002). The factor structure underlying three self-report multicultural counseling competence scales. Cultural Diversity \& Ethnic Minority Psychology, 8, 334-345.

Constantine, M. G., \& Ladany, N. (2000). Self-report multicultural counseling competence scales: Their relation to social desirability attitudes and multicultural case conceptualization ability. Journal of Counseling Psychology, 47, 155-164.

Cumming-McCann, A. A. (1999). Multicultural counseling competencies and racial identity development of practicing vocational rehabilitation counselors (Doctoral 
dissertation, University of Northern Colorado, 1999). Dissertation Abstracts International, 60, 2383.

D'Andrea, M., Daniels, J., \& Heck, R. (1991). Evaluating the impact of multicultural counseling training. Journal of Counseling and Development, 70, 143-150.

Darcy, M., Lee, D., \& Tracey, T. J. G. (2004). Complementary approaches to individual differences using paired comparisons and multidimensional scaling: Applications to multicultural counseling competence. Journal of Counseling Psychology, 51, 139-150.

Fuertes, J. N., \& Brobst, K. (2002). Clients' ratings of counselor multicultural competency. Cultural Diversity \& Ethnic Minority Psychology, 8, 214-223.

Garcia, J. A. (1997). In search of cross-cultural competency: An empirical examination of cross-cultural training efforts in social work education (Doctoral dissertation, University of Southern California, 1996). Dissertation Abstracts International, $57,3842$.

Granello, D. H., \& Wheaton, J. E. (1998). Self-perceived multicultural competencies of African American and European American vocational rehabilitation counselors. Rehabilitation Counseling Bulletin, 42, 2-15.

Guilford, J. P, \& Fruchter, B. (1978). Fundamental statistics in psychology and education (6 $6^{\text {th }}$ ed.). New York: McGraw-Hill.

Gutierrez, B. M. (1996). Reported experiences which influence psychologists' degree of multicultural competency (Doctoral dissertation, Texas A\&M University, 1996). Dissertation Abstracts International, 58, 96. 
Holcomb-McCoy, C. (2004). Assessing the multicultural competence of school counselors: A checklist. Professional School Counseling, 7, 178-186.

Holcomb-McCoy, C. C., \& Myers, J. E. (1999). Multicultural competence and counselor training: A national survey. Journal of Counseling and Development, 77, 294302.

Kim, B. S. K., Cartwright, B. Y., Asay, P. A., \& D’Andrea, M. J. (2003). A revision of the Multicultural Awareness, Knowledge, and Skills Survey-Counselor Edition. Measurement and Evaluation in Counseling and Development, 36, 161-180.

Kocarek, C. E., Talbot, D. M., Batka, J. C, \& Anderson, M. Z. (2001). Reliability and validity of three measures of multicultural competency. Journal of Counseling and Development, 79, 486-496.

LaFromboise, T. D., Coleman, H. L., \& Hernandez, A. (1991). Development and factor structure of the Cross-Cultural Counseling Inventory--Revised. Professional Psychology: Research and Practice, 22, 380-388.

Martinez, M. Y. (1995). The application of a psychologically based model for crosscultural counseling training within rehabilitation counselor education (Doctoral dissertation, University of Arizona, 1995). Dissertation Abstracts International, 56, 3839.

Martinez, R. (1997). Development of a Psychotherapist Multicultural Attitudes Inventory (Doctoral dissertation, University of Wisconsin-Madison, 1997). Dissertation Abstracts International, 58, 3363.

McCrae, R. R., \& Costa, P. T. (1983). Social desirability scales: More substance than style. Journal of Consulting \& Clinical Psychology, 51, 882-888. 
Miville, M. L., Gelso, C. J., Pannu, R., Liu, W., Touradji, P., Holloway, P., \& Fuertes, J. (1999). Appreciating similarities and valuing differences: The Miville-Guzman Universality-Diversity Scale. Journal of Counseling Psychology, 46, 291-307.

Ponterotto, J. G. (1996). Evaluating and selecting research instruments. In F. T. L. Leong, \& J. T. Austin (Eds.), The psychology research handbook: A guide for graduate students and research assistants (pp. 73-84). Thousand Oaks, CA: Sage.

Ponterotto, J. G., \& Alexander, C. M. (1996). Assessing the multicultural competence of counselors and clinicians. In L. A. Suzuki, P. J. Meller, \& J. G. Ponterotto (Eds.), Handbook of Multicultural Assessment (pp. 651-672). San Francisco: JosseyBass.

Ponterotto, J. G., Gretchen, D., Utsey, S. O., Rieger, B. P., \& Austin, R. (2002). A revision of the Multicultural Counseling Awareness Scale. Journal of Multicultural Counseling and Development, 30(3), 153-180.

Ponterotto, J. G., Rieger, B. P., Barrett, A., Harris, G., Sparks, R., Sanchez, C. M., \& Magids, D. (1996). Development and initial validation of the Multicultural Counseling Awareness Scale. In G. R. Sodowsky, \& J. C. Impara (Eds.). Multicultural Assessment in Counseling and Clinical Psychology (pp. 247- 282). University of Nebraska-Lincoln: Buros Institute of Mental Measurements.

Ponterotto, J. G., Rieger, B. P., Barrett, A., \& Sparks, R. (1994). Assessing multicultural counseling competence: A review of instrumentation. Journal of Counseling \& Development, 72, 316-322.

Pope-Davis, D. B., \& Dings, J. G. (1994). An empirical comparison of two self-report multicultural counseling competency inventories. Measurement and Evaluation in 
Counseling and Development, 27, 93-102.

Pope-Davis, D. B., \& Dings, J. G. (1995). The assessment of multicultural counseling competencies. In J. G. Ponterotto, J. M. Casas, L. Suzuki, \& C. Alexander (Eds.), Handbook of multicultural counseling (pp. 287-311). Thousand Oaks, CA: Sage.

Pope-Davis, D. B., Toporek, R. L., Ortega-Villalobos, L., Ligiero, D. P., Brittan-Powell, C. S., Liu, W. M., Bashshur, M. R., Codrington, J. N., Liang, C. T. H. (2002). Client perspectives of multicultural counseling competence: A qualitative examination. Counseling Psychologist, 30, 355-393.

Pruegger, V. J., \& Rogers, T. B. (1994). Cross-cultural sensitivity training: Methods and assessment. International Journal of Intercultural Relations, 18, 369-387.

Reynolds, A. L. (2001). Multidimensional cultural competence: Providing tools for transforming psychology. Counseling Psychologist, 29, 833-841.

Robinson, D. T. (1999). The relationship between multicultural counseling competencies and attitudes toward African Americans among white female graduate students (Doctoral dissertation, Western Michigan University, 1999). Dissertation Abstracts International, 60, 3919.

Rogers, M. R., \& Ponterotto, J. G. (1997). Development of the multicultural school psychology counseling competency scale. Psychology in the Schools, 34, 211217.

Roussos, L., \& Stout, W. (1996). A multidimensionality-based DIF analysis paradigm, Applied Psychological Measurement, 20, 355-371.

Smith, D. B., Ellingson, J. E. (2002). Substance versus style: A new look at social desirability in motivating contexts. Journal of Applied Psychology, 87, 211-219. 
Sodowsky, G. R. (1996). The multicultural counseling inventory: Validity and applications in multicultural training. In G. R. Sodowsky, \& J. C. Impara (Eds.). Multicultural Assessment in Counseling and Clinical Psychology (pp. 283-324). University of Nebraska-Lincoln: Buros Institute of Mental Measurements.

Sodowsky, G. R., Kuo-Jackson, P. Y., Richardson, M. F., \& Corey, A. T. (1998). Correlates of self-reported multicultural competencies: Counselor multicultural social desirability, race, social inadequacy, locus of control racial ideology, and multicultural training. Journal of Counseling Psychology, 45, 256-264.

Sodowsky, G. R., Taffe, R. C., Gutkin, T. B., \& Wise, S. L. (1994). Development of the Multicultural Counseling Inventory: A self-report measure of multicultural competencies. Journal of Counseling Psychology, 41, 137-148.

Sue, D. W., Arredondo, P., \& McDavis, R. J. (1992). Multicultural counseling competencies and standards: A call to the profession. Journal of Multicultural Counseling and Development, 20, 64-88.

Sue, D. W., Bernier, J. E., Durran, A., Feinberg, L., Pedersen, P., Smith, E. J., \& Vasquez-Nuttall, E. (1982). Position paper: Cross-cultural counseling competencies. The Counseling Psychologist, 10, 45-52.

Sue, S. (2003). In defense of cultural competency in psychotherapy and treatment. American Psychologist, 58, 964-970.

Talbot, D. M. (1992). A multimethod study of the diversity emphasis in master's degree programs in college student affairs (Doctoral dissertation, University of Maryland College Park, 1992). Dissertation Abstracts International, 53, 2198.

Talbot, D. M. (1996). Master's students' perspectives on their graduate education 
regarding issues of diversity. NASPA Journal, 33, 163-178.

Talbot, D. M., \& Kocarek, C. (1997). Student affairs graduate faculty members' knowledge, comfort, and behaviors regarding issues of diversity. Journal of College Student Development, 38, 278-287.

Thorn, G. R. (1996). The relationship between working alliance, cross-cultural counseling competency, referral sources, and racial identity attitudes: Psychotherapy with African-American males (Doctoral dissertation, University of Nebraska, 1996). Dissertation Abstracts International, 57, 5934.

Vacha-Haase, T. (1998). Reliability generalization: Exploring variance in measurement error affecting score reliability across studies. Educational and Psychological Measurement, 58, 6-20.

Velez, E. R. (2003). Multicultural counseling competencies of doctoral school psychology interns and their primary supervisors (Doctoral dissertation, University of Maryland, College Park, 2002). Dissertation Abstracts International, 63, 3826.

Wheaton, J. E., \& Granello, D. H. (1998). The multicultural counseling competencies of state vocational rehabilitation counselors. Rehabilitation Education, 12, 51-64.

Worthington, R. L., Mobley, M., Franks, R. P., \& Tan, J. A. (2000). Multicultural counseling competencies: Verbal content, counselor attributions, and social desirability. Journal of Counseling Psychology, 47, 460-468. 
Table 1

Characteristics of Studies Included in the Quantitative Review

Characteristic

Year of Study

$$
1990-1994
$$

$1994-1999$

$2000-2003$

Purpose of Study

Evaluate multicultural training and/or supervision 42

Investigate construct of multicultural competency

Investigate professional competence

Evaluate multicultural competency instrument

Multicultural competency effect on therapy process/outcome

Combination of above categories

Other

Population Sampled

Clinical trainees

Practicing clinicians/faculty

Clinical trainees and practicing clinicians/faculty

Clients

Third-party observer

Sampling Procedure Used

Convenience

102

33

Random 3 
Table 1 (continued)

Characteristics of Studies Included in the Quantitative Review

Characteristic

$K^{\mathrm{a}}$

$\%$

Sample size

$<50$

27

20

$50-100$

31

23

$100-250$

57

42

$>250$

22

16

Research Design

Cross-sectional

85

62

Experimental

17

12

Comparison groups

12

9

Pre-post test

10

7

Other (e.g., longitudinal, archival)

13

9

Most Frequently Used Instruments, 1990-2003 b

Multicultural Counseling Inventory

56

Multicultural Awareness Knowledge and Skills Survey

29

Cross-Cultural Counseling Competence Inventory-Revised ${ }^{\mathrm{C}}$

28

Multicultural Counseling Knowledge and Awareness Scale ${ }^{\mathrm{d}}$

21

18

Survey of Graduate Students' Experiences with Diversity

4

3

Multicultural Counseling Competence and Training

3

2

${ }^{\mathrm{a}}$ Number of studies out of 137 total that quantitatively assessed multicultural competence. ${ }^{\mathrm{b}}$ Reports only those instruments used more than once in the literature; numbers do not sum to 137 because some studies used more than one instrument. ' Includes two uses of the CCCI and eight uses of the CCCI-R as a self-report instrument. ${ }^{\mathrm{d}}$ Includes two uses of the MCAS and seven uses of the MCAS:B. 
Table 2

Mean Internal Consistency Reliability for Most Commonly Used Instruments and Their Subscales

\begin{tabular}{|c|c|c|c|c|c|}
\hline Name of Instrument & $\mathrm{K}^{\mathrm{a}}$ & Mean & $\mathrm{SD}$ & Minimum & Maximum \\
\hline Multicultural Counseling Inventory & 26 & .863 & .042 & .75 & .95 \\
\hline Knowledge Subscale & 34 & .763 & .107 & .23 & .88 \\
\hline Skills Subscale & 34 & .788 & .053 & .62 & .95 \\
\hline Awareness Subscale & 34 & .779 & .069 & .50 & .90 \\
\hline Relationship Subscale & 34 & .653 & .056 & .55 & .78 \\
\hline Multicultural Awareness Knowledge and Skills Survey & 10 & .890 & .019 & .86 & .92 \\
\hline Knowledge Subscale & 19 & .776 & .122 & .32 & .90 \\
\hline Skills Subscale & 17 & .905 & .023 & .87 & .96 \\
\hline Awareness Subscale & 19 & 639 & .094 & .47 & .78 \\
\hline Multicultural Counseling Knowledge and Awareness Scale & 6 & .880 & .033 & .83 & .91 \\
\hline Knowledge Subscale & 9 & .886 & .030 & .85 & .93 \\
\hline Awareness Subscale & 9 & .797 & .065 & .71 & .89 \\
\hline Cross-Cultural Counseling Competence Inventory-Revised ${ }^{\mathrm{b}}$ & 17 & .914 & .050 & .79 & .97 \\
\hline Total $^{\mathrm{C}}$ & 322 & .795 & .112 & .23 & .97 \\
\hline
\end{tabular}

${ }^{a}$ Number of studies that report internal consistency reliability information. ${ }^{\mathrm{b}}$ Includes five uses of the CCCI-R as a self-report instrument. ${ }^{\mathrm{c}}$ Total includes all internal consistency reliability coefficients reported $(N=322)$. 
Table 3

Average Inter-Scale Correlation Coefficients of the MCI, MAKSS, MCKAS, and CCCI-R

\begin{tabular}{|c|c|c|c|c|c|c|c|c|c|c|c|c|c|c|}
\hline Variables & 1 & 2 & 3 & 4 & 5 & 6 & 7 & 8 & 9 & 10 & 11 & 12 & 13 & 14 \\
\hline 1. MCI: Total & - & & & & & & & & & & & & & \\
\hline 2. MCI: Knowledge Subscale & .81 & - & & & & & & & & & & & & \\
\hline 3. MCI: Skills Subscale & .80 & .51 & - & & & & & & & & & & & \\
\hline 4. MCI: Awareness Subscale & .82 & .47 & .42 & - & & & & & & & & & & \\
\hline 5. MCI: Relationship Subscale & .64 & .25 & .39 & .29 & - & & & & & & & & & \\
\hline 6. MAKSS: Total & .70 & .61 & .54 & .60 & .36 & - & & & & & & & & \\
\hline 7. MAKSS: Knowledge Subscale & .55 & .51 & .43 & .49 & .23 & .88 & - & & & & & & & \\
\hline 8. MAKSS: Skills Subscale & .66 & .50 & .55 & .54 & .43 & .87 & .51 & - & & & & & & \\
\hline 9. MAKSS: Awareness Subscale & .51 & .54 & .33 & .46 & .20 & .73 & .47 & .41 & - & & & & & \\
\hline 10. MCKAS: Total & .64 & .66 & .46 & .53 & .22 & .72 & .63 & .54 & .67 & - & & & & \\
\hline 11. MCKAS: Knowledge Subscale & .69 & .60 & .48 & .55 & .29 & .74 & .65 & .59 & .63 & .93 & 一. & & & \\
\hline 12. MCKAS: Awareness Subscale & .18 & .33 & .12 & .05 & .23 & .33 & .29 & .18 & .43 & .65 & 29 & - & & \\
\hline 13. CCCI-R Self-Report Form & .73 & .63 & .56 & .62 & .43 & .71 & .60 & .65 & .50 & .61 & .65 & .19 & - & \\
\hline 14. CCCI-R Observer Rated Form & .04 & .13 & -.03 & .15 & -.11 & & & & & & & & & - \\
\hline
\end{tabular}

